\title{
LA ORDENACIÓN DEL ESPACIO AGRARIO EN ECONOMÍAS PREINDUSTRIALES. EL CASO DEL CULTIVO DEL OLIVO EN EL SUR DE ESPAÑA ${ }^{1}$
}

\author{
Management of agricultural area in preindustrial economies. The case of olive orchards \\ in southern Spain
}

\author{
Juan Infante Amate \\ Universidad Pablo de Olavide \\ jinfama@upo.es \\ Fecha de recepción: $15-I V-2012$ \\ Fecha de aceptación: 22-IV-2012
}

Resumen: En las últimas décadas se ha desarrollado una literatura especializada en el estudio de las particulares características de las agriculturas preindustriales. Este trabajo, en base a la citada línea de trabajo, analiza los plantíos de olivar andaluces, que hoy representan la mayor concentración arbórea de Europa, justo en el momento previo a su gran expansión (mediados del siglo XVIII). Intentamos aportar claves que expliquen la geografía de expansión: su escasa superficie antes de la industrialización y las causas de porqué algunos puntos de Andalucía se erigieron como focos prematuros de especialización.

Palabras clave: historia del paisaje, olivar, geografía agraria, historia rural, historia ambiental.

ABSTRACT: In recent decades it has been developed a specialized literature on the study of particular features of preindustrial agricultures. This paper, in base to such research line, analyzes the case of olive orchards in southern Spain, which today represent the largest tree concentration in Europe, right in the previous moment to its great expansion (mid $18^{\text {th }}$

1 Agradezco los comentarios de Manuel González de Molina y David Soto. Los errores persistentes son responsabilidad única del autor. El trabajo se enmarca en el proyecto HAR2009-13748-C03-03 (Ministerio de Innovación, Ciencia y Tecnología). 
Century). We seek to understand the geography of its spreading, its low expansion before industrialization and the why only few territories on Andalusia appeared like premature focus of specialization.

Keywords: history of landscape, olive tree, agrarian geography, rural history, environmental history.

\section{INTRODUCCIÓN}

Decía el poeta francés Georges Duhamel que «donde el olivo se retira acaba el mediterráneo» ${ }^{2}$. Se cuenta que la primera variedad cultivada por el hombre del árbol del olivo (Olea Europaea ssp.e.v.e.) apareció en Oriente próximo hace unos 5500 años (Zohary and Hopf, 1994). Aunque hoy en día sigue abierto el debate sobre el lugar preciso donde se desarrolló originalmente, sí parece claro que su expansión vino de la mano de la domesticación de variedades silvestres como los acebuches que, desde milenios atrás, ya poblaban de forma espontánea los bosques mediterráneos (Bersnard et al., 2001; Bersnard and Bervillé, 2000).

El olivo y mundo mediterráneo forman parte de un relato paralelo (Angles, 1999). Hoy en día, de cada 10 olivos plantados en el mundo, alrededor de 9 crecen en el Mediterráneo (IOOC, 2010). Aún así, aunque buena parte de la historiografía relaciona este árbol con el mundo clásico, las últimas recopilaciones sobre usos del suelo nos informan de que su expansión en forma de monocultivo intensivo data solo de las últimas décadas. Es más, el paisaje monocultural del olivo que hoy preside los campos del sur de España no tiene su origen en la Antigüedad sino que empezó a erigirse a finales del siglo XIX (Guzmán, 2004; Infante, 2011, 2012; Zambrana, 1987, 2006). Sin tratar de restar importancia al secular papel del olivo y el aceite, presumimos que dentro de la famosa trilogía mediterránea el árbol de Minerva ocupaba un espacio menor.

En los últimos años han proliferado trabajos de gran influencia en el campo de la historia agraria que, haciendo uso de una perspectiva ambiental, han descrito un funcionamiento particular de las agriculturas preindustriales poniendo de manifiesto ciertos límites para su crecimiento, comercio o especialización agrícola. Según estos trabajos la posibilidad de expansión

2 Citado en Mataix y Barbancho (2007, p. 707). 
olivarera estaría seriamente coartada hasta la industrialización agrícola. En este texto queremos examinar el plantío de olivar en un contexto preindustrial para saber si, en efecto, estos limitantes explican su débil expansión, los lugares donde la especialización surgió con mayor intensidad y las diferentes tipologías de olivar existentes en la época.

Para ello haremos uso de diferentes estudios de caso representativos de las dispares «agriculturas andaluzas». Numerosos trabajos ya han puesto de manifiesto la heterogeneidad del agro andaluz: zonas de campiña vs zonas de sierra, Alta y Baja Andalucía, economías campesinas y economías jornaleras ${ }^{3}$. Nuestros estudios de caso son el municipio de Castilleja de la Cuesta en el Aljarafe sevillano como lugar portuario sometido al influjo mercantil de la ciudad de Sevilla a mediados del siglo XVIII; el municipio cordobés de Baena, ejemplo de la Andalucía de campiña, de gran propiedad y prematura colonización agrícola; finalmente, el municipio granadino de Montefrío. Sito en la comarca de Los Montes Orientales de Granada representa un caso conocido de agricultura de montaña, campesina, aislada y obligada a la producción de sustento.

El ámbito temporal se circunscribe a mediados del siglo XVIII. Hacemos uso, obviamente, del Catastro del Marqués de la Ensenada. Sus Respuestas Generales ofrecen detalladas descripciones sobre la agricultura local y, en base a las Respuestas Particulares, podemos reconstruir propietario a propietario los usos del suelo y otras particularidades. Hemos recopilado información de los Protocolos Notariales para cada estudio de caso con el objeto de conocer con más profundidad los aprovechamientos agrarios de cada municipio. Secciones como los Inventarios Postmortem o los contratos de Arrendamiento son herramientas útiles para profundizar en la disposición de los plantíos durante este período.

3 Son conocidos los clásicos trabajos sobre la campiña andaluza (véanse entre los más destacados: Bernal, 1979; Bernal y Drain, 1975; Cruz Villalón, 1980, 1991; Mata Olmo, 1987; Ponsot, 1986). En los últimos años otros muchos han reivindicado, por su parte, la dispar evolución seguida por las zonas de la sierra Altoandaluza (véase por ejemplo: González de Molina, 2010a,b; González de Molina y Sevilla, 1991; Martínez, 1995). 


\section{Sobre El FUNCIONAMIENTO DE LA AGRICULTURA PREINDUSTRIALES}

En los años 80 se publicaron un par de libros que han ejercido una notabilísima influencia en el estudio de las agriculturas preindustriales ${ }^{4}$. De aquel tiempo a esta parte se han multiplicado los trabajos herederos de tales planteamientos, detallando una serie de particularidades en las mismas que ponían de manifiesto unos rígidos limitantes sobre las posibilidades de crecimiento, transporte o proliferación de monocultivos ${ }^{5}$.

Las economías preindustriales tenían una plena dependencia de la producción agraria para completar las demandas de la población. Los alimentos, las fibras, los materiales de construcción, los medicamentos o los combustibles provenían, en su práctica totalidad, del sistema agrario. Se estima que un $95 \%$ de los requerimientos energéticos provenían, durante este período, de fuentes orgánicas (Krausmann et al, 2009). La principal característica de la agricultura desde su invención hace 10000 años hasta la plena industrialización agrícola hace pocas décadas, ha sido la plena dependencia de la energía solar. Así las cosas la economía preindustrial ha sido adjetivada, atendiendo a este limitante, como «organic economy» (Wriley, 1988), «controlled solar energy system» (Sieferle, 2001), «land-based energy system» (Fischer-Kowalsky et al., 2007) o «vegetable energy system» (Malanima, 2001).

La primera implicación de este régimen productivo era la escasa posibilidad de establecer fluidas redes comerciales entre los territorios. La fuerza animal aparecía como la única fórmula de transporte terrestre y, así pues, la capacidad para desplazar a personas o mercancías estaba restringida. Operaba una suerte de «ley de hierro del transporte» que impedía movilizar más energía de la que los animales consumirían en su trayecto (Sieferle, 2001, p. 59). Principalmente en el caso de los granos, alimento animal.

Hay sobradas evidencias de la existencia de migraciones o relaciones mercantiles entre territorios antes del período industrial (con ferrocarriles u

4 Sieferle (1988[2001]) y Wrigley (1988).

5 Imposible citar aquí todos los trabajos. Entre los más recientes e influyentes: Cussó et al., 2006; Fischer-Kowalsky et al., 2007, pp. 225-230; González de Molina, 2010; González de Molina y Guzmán, 2006; Jones, 2010; Krausmann, 2001, 2004; Krausmann et al, 2008, p. 188-191; Tello et al., 2001; Sieferle, 1990, 2001; Pfister, 1990; Warde, 2009. Nótese que los dos trabajos citados de Siferle y Wrigley han sido reeditados en 2010 ante la notable influencia de sus planteamientos. 
otros transportes movidos con energías fósiles) pero lo cierto es que el que el mayor porcentaje del consumo en cualquier región provenía de la producción doméstica (Fischer-Kowalsky et al., 2007:228). Si analizamos los flujos comerciales de los primeros imperios coloniales podemos observar cómo el grueso de las importaciones estaba compuesto por lo que Wallerstein llamó «preciosities», esto es, aquellos productos que eran claves para determinados grupos sociales o para el funcionamiento de las economías occidentales y que justificaban altos costes en su transporte como, por ejemplo, ciertos metales preciosos, las especias o el guano (Martínez Alier, 2007:232).

Se ha estimado que el transporte por tierra para el resto de mercancías no debía superar, en general, los 10-50 Km (Fischer-Kowalski, et al, 2007:227). En este sentido el acceso al mar o a los ríos fue decisivo para quebrar estos límites (Bagwell, 1974). El transporte marítimo y fluvial era menos costoso pero, aún así, también contaba con importantes limitaciones para establecer redes comerciales de gran alcance (Smil, 2001).

En suma, las economías preindustriales tenían severas limitaciones para importar energía y materiales de otros territorios y, en consecuencia, debían organizar sus aprovechamientos agrícolas de manera que pudieran proveer a sus regiones de la mayoría de bienes necesarios para completar su sustento. Aparece así un segundo rasgo distintivo de las agriculturas preindustriales: la obligada «integración agrosilvopastoral» (Guzmán y González de Molina, 2009) y la división clásica de los territorios apropiados en base al ager-saltussilva. Ager (tierra cultivada), saltus (dedicada al aprovechamiento pecuario) y silva (donde se realizaban los aprovechamientos forestales, la recolección y la cacería).

En suma: la mayoría de territorios en los siglos precedentes a la industrialización dependerían, para satisfacer las necesidades de sus habitantes, de la producción agraria; tendrían una limitada capacidad para establecer redes mercantiles los que, en consecuencia, obligaba a una conjugación de usos del suelo para producir múltiples bienes. 


\section{El olivar en el Aljarafe sevillano}

\subsection{Una disonancia paisajística: la agricultura del Aljarafe a mediados del siglo XVII}

El municipio de Castilleja de la Cuesta se encuentra en el corazón de la comarca del Aljarafe sevillano, entre una concentración de municipios situados al oeste de la ciudad de Sevilla, sobre una leve colina que se levanta una vez cruzado el río Guadalquivir. Su cercanía a la capital hispalense ha convertido a este municipio y su comarca en una disonancia histórica difícilmente abordable desde el punto de vista de la distribución de los usos del suelo y la lógica de los aprovechamientos agrarios a mediados del siglo XVIII. Altas densidades de población, niveles de «agricolización» extremos y rendimientos de algunos cultivos que no se verán en otras partes de Andalucía hasta el siglo XX. Una estructura agraria que rompe con los presupuestos que cabría esperar cuando miramos las agriculturas andaluzas del siglo XVIII tal y como acabamos de explicar más arriba.

Hoy en día, entrando en la segunda década del siglo XXI, la provincia de Sevilla cuenta con una densidad de $135 \mathrm{hab} / \mathrm{km}^{2}$. Castilleja de la Cuesta contaba, en 1752, exactamente, con $461 \mathrm{hab} / \mathrm{km}^{2}$. Además, añadamos que la superficie cultivada suponía el 100\% de la SAU. Nada dedicado a pastos, nada dedicado a usos forestales. De las 200 ha cultivadas casi dos terceras partes se destinaban a cultivos comerciales como la vid y el olivar.

El municipio contaba en 1752 con 75 ha de cereal para alimentar a 130 cabezas de ganado y a casi mil personas. Sin necesidad de hacer prolijos cálculos las 0,22 ha/hab disponibles o los $461 \mathrm{hab} / \mathrm{km}^{2}$ no permiten, con mucho, una suficiencia alimentaria derivada de los usos del suelo del lugar. Recordemos que, de acuerdo con Ester Boserup (1984), la densidad de población que empezaba a comprometer la subsistencia de una comunidad eran $65 \mathrm{hab} / \mathrm{km}^{2}$. Sin olvidar el hecho de que prácticamente no existía la cabaña de renta, no había pastizales y tampoco zonas forestales. Es evidente que el obligado equilibrio territorial de una agricultura orgánica se extendía más allá de los límites municipales. En realidad, no es de extrañar cuando se está a menos de $10 \mathrm{~km}$ de una de las ciudades más importantes de España, con el único puerto fluvial de interior que había ejercido el monopolio con las Américas y, sobre todo, contando con 200 ha de extensión. Habremos de mirar a territorios adyacentes en busca del obligado equilibrio productivo: analizamos ahora la totalidad de la comarca del Aljarafe. 
Cuadro 1. Datos sobre población, usos del suelo y cabaña ganadera en Castilleja, 1752.

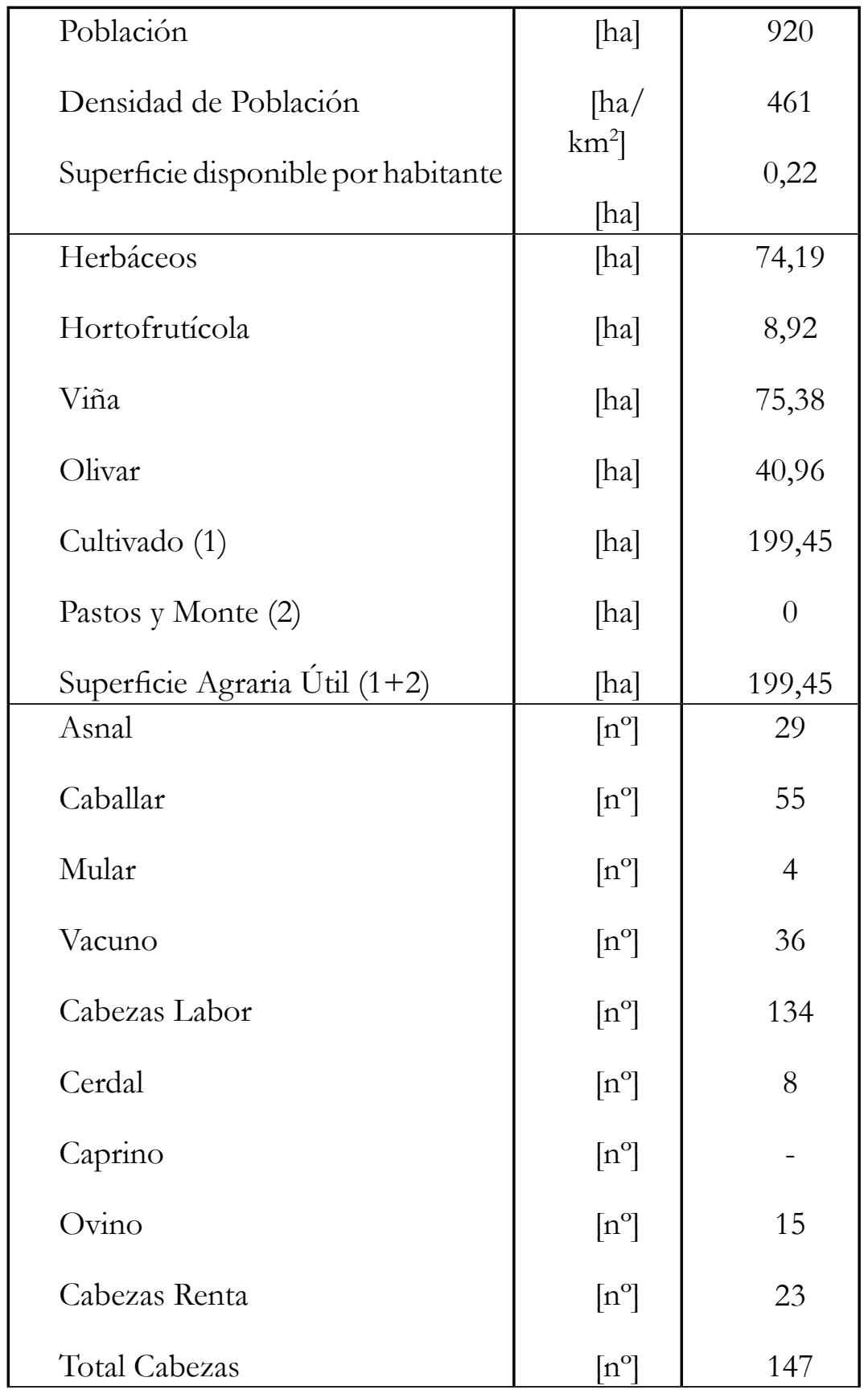

Fuente: Catastro del Marqués de la Ensenada, Castilleja de la Cuesta, 1752. AMCC. 
Tal y como señaló Sieferle (2001), en el contexto de economías preindustriales, cuanto más intensivo era el uso del territorio y más especializado estaba más necesidad tenía de expandir su frontera comercial hacia otras zonas para garantizar el abastecimiento de otros productos. Para hacer más operativo nuestro análisis hemos divido la comarca en tres zonas geográficas según la distancia de cada una de la ciudad de Sevilla. De esta manera hemos considerado como «Aljarafe 1» a los 13 municipios más cercanos a la ciudad. Estos quedan a una media de 8,62 km. El «Aljarafe 2» se compone de los 19 siguientes municipios y se ubica a una media de $19,21 \mathrm{~km}$. Finalmente, el «Aljarafe 3» a una media de $30,58 \mathrm{~km}$, cuenta con 12 municipios más.

De la estructura propuesta se derivan tres semicírculos concéntricos que guardan una pauta común: cuanto mayor sea la distancia de la capital sevillana, esto es, del «centro», menos densidad de población y mayor tamaño tendrá la sucesiva periferia. Así las cosas, el primer anillo contará con una densidad de población de $55 \mathrm{hab} / \mathrm{km}^{2}$, el segundo baja hasta los $42 \mathrm{hab} /$ $\mathrm{km}^{2}$ y el tercero se queda solo en $12 \mathrm{hab} / \mathrm{km}^{2}$. Los pueblos ubicados en la periferia más extrema representan un total de 65.719 ha de la comarca, o lo que es igual, dos terceras partes de la misma. Aún así, cuentan con menos de un tercio de la población del Aljarafe. El primer círculo con solo un 10\% de la superficie comarcal es residencia de una cuarta parte de la población. 


\section{Cuadro 2. Indicadores sobre la superficie y la población en la comarca del Aljarafe. 1750.}

\begin{tabular}{|c|c|c|c|c|c|}
\hline & & $\begin{array}{l}\text { Aljaraf } \\
\text { e } 1\end{array}$ & $\begin{array}{l}\text { Aljaraf } \\
\text { e } 2\end{array}$ & $\begin{array}{l}\text { Aljaraf } \\
\text { e } 3\end{array}$ & $\begin{array}{l}\text { Aljarafe } \\
\text { Total }\end{array}$ \\
\hline Municipios & {$\left[\mathrm{n}^{\circ}\right]$} & 13 & 19 & 12 & 44 \\
\hline Población & {$\left[\mathrm{n}^{\circ}\right]$} & 5.740 & 9.904 & 7.852 & 23.496 \\
\hline Densidad de Población & $\begin{array}{l}{\left[\mathrm{hab} / \mathrm{km}^{2}\right.} \\
]\end{array}$ & 54,9 & 42,4 & 12,1 & 23,84 \\
\hline Superficie Total & [ha] & 10.453 & 23.380 & 64.720 & 98.552 \\
\hline Superficie Media [ha] & [ha] & 804 & 1231 & 5393 & 2240 \\
\hline$\%$ Superficie Total & {$[\%]$} & 10,6 & 23,7 & 65,7 & 100,0 \\
\hline $\begin{array}{l}\text { Distancia Media de } \\
\text { Sevilla }\end{array}$ & {$[\mathrm{km}]$} & 8,6 & 19,2 & 30,6 & 19,2 \\
\hline Herbáceos & $\begin{array}{l}{[\% \text { del }} \\
\text { total }]\end{array}$ & 38,8 & 55,0 & 29,9 & 36,8 \\
\hline Leñosos y riego & {$[\%$ del } & 57,1 & 16,2 & 5,5 & 13,5 \\
\hline (Olivar) & total] & $(37,3)$ & $(12,9)$ & $(12,7)$ & $(17,8)$ \\
\hline Cultivado & $\begin{array}{l}{[\% \text { del }} \\
\text { total }]\end{array}$ & 95,8 & 71,2 & 35,4 & 50,3 \\
\hline Silvopastoral & {$[\% \operatorname{del}$} & 4,3 & 28,8 & 64,6 & 49,7 \\
\hline Total & $\begin{array}{l}\text { total] } \\
{[\% \text { del }} \\
\text { total] } \\
{[\% \text { de1 }} \\
\text { total] }\end{array}$ & 100,0 & 100,00 & 100,0 & 100,0 \\
\hline
\end{tabular}

Fuente: Respuestas Generales del Catastro del Marqués de la Ensenada. Varios municipios. Consulta a través de la página web del Ministerio de Cultura y la red «pares».

Los pueblos más cercanos a la capital difícilmente podrían completar su sustento con un arreglo territorial que solo los proveía de cereal y, en mayor grado, de cultivos comerciales como la vid y el olivar. La gran reserva de mano de obra encontrada en esta zona de la provincia de Sevilla así como la cabaña ganadera de renta focalizaba su actividad en poner en funcionamiento tierras de cultivo que abastecían a la ciudad de Sevilla y al comercio con las Indias. Resultan más comprensibles ahora los datos de A.M. Bernal y García 
Baquero cuando apuntaban que en tiempos de Ensenada un $90 \%$ de las exportaciones de aceite allende el Atlántico provenían, sobre todo, de la provincia de Sevilla (Bernal y García Baquero, 1976). Este comercio data del siglo XVI y, al parecer, la periferia sevillana anticipaba una especialización productiva de alta intensidad en labores e insumos volcada a las redes mercantiles transnacionales que cruzaban el océano.

Sin embargo, el nivel de intensidad agraria pierde fuerza a medida que nos alejamos de la capital. Así las cosas, en la primera línea, todos los pueblos cultivan más de un $80 \%$ de su SAU y casi la mitad cultiva el 100\%. En la segunda línea, el nivel de «agricolización» se reduce: aquí, la mitad de los municipios solo cultivan entre el 30\% y el $80 \%$. En el anillo final no se cultiva, por lo general, más del $50 \%$.

En la medida en que el nivel de «agricolización»es menos intenso, la superficie destinada a monte o pasto se incrementa. Empezamos, ahora a sí, a entender mejor la ordenación territorial del municipio de Castilleja de la Cuesta una vez que abrimos la unidad de análisis de las 200 ha del pueblo a las casi 100.000 ha de la comarca. La integración paisajística es un hecho cuando comprobamos cómo la periferia más lejana tenía una clara vocación forestal y ganadera con la que, es de suponer, se suplirían las demandas de combustibles, carne, leche y similares de la metrópolis.

La comarca del Aljarafe en su totalidad, como era de esperar, guarda una clara similitud con la ordenación del territorio del resto de Andalucía con un $50 \%$ de su superficie total cultivada y el resto destinada a pastos y montes que completan las necesidades de sustento propias de agriculturas orgánicas. Sin embargo, el influjo mercantil de Sevilla y su puerto forzaron un mosaico de usos del suelo poco habitual en este período teniendo que integrar a territorios situados a más de $30 \mathrm{~km}$ de la capital para garantizar la integración entre los cultivos agrícolas, silvícolas y pastorales. Así pues, esos trece municipios más próximos a Sevilla representaban una disonancia histórica en tanto en cuanto destinaban un $96 \%$ de su superficie total a cultivos. Más de 10.000 ha de un total de 10.452 ha. Sin embargo, los municipios más alejados de la capital apenas cultivan un tercio de sus tierras, con rotaciones poco intensivas, lo que representa una media incluso inferior al resto de Andalucía. Más de un $60 \%$ de su superficie se destinaba a partes iguales entre pastos y montes a fin de contrarrestar los desequilibrios de la metrópolis 
exportando carbones vegetales, ganado de renta e, indirectamente, ganado de labor.

Contamos con ciertas evidencias que sostienen esta hipótesis sobre los flujos de mercancías entre los municipios del Aljarafe y la ciudad de Sevilla. Según las entrevistas realizadas por Infante (2011) a ciertos agricultores de la zona, hasta hace pocos años, llegaban a los municipios del Aljarafe 1, combustibles y maderas que provenían del Aljarafe 3. Nos recordaban que todavía "aqui hay un camino que le dicen el camino de los carboneros y que va en esa dirección: Aznalcázar, Serena, Arroyo de la Plata...». Aznalcázar, municipio situado en la periferia más lejana del Aljarafe contaba en 1752 con una gran dehesa que hoy en día sigue existiendo (ver fotografía 1) y que hasta hace pocos años suministraba combustible a las zonas aledañas a la ciudad de Sevilla. En Tomares (pueblo del Aljarafe 1), por ejemplo, se apuntaba que «venían los carboneros y traían carbón de encina. Venian en invierno vendiéndolos (...). Venian de Bollullos para arriba, más que nada de Benazacón (...). Venian a los pueblos con bestias. Algunos de Almonte. Desde Bormujos venían a Tomares».

Esta estrategia en los usos del suelo que terminaba por afectar a muchos municipios entorno a una gran ciudad responde a una pauta común descrita para otras ciudades Europeas bajo agriculturas preindustriales. Así, Haberl y Krausmann (2007, p. 127) han estimado que Viena, a principios del siglo XIX, requería por habitante para satisfacer sus consumos entre 1,5 y 2 ha/año. Sin embargo, la superficie disponible en la ciudad apenas era de $0,2 \mathrm{ha} / \mathrm{hab} / \mathrm{año}$. Era preciso importar alimentos y combustibles de las zonas periféricas. Para el caso de París, Billen et al. (2009), han identificado este impacto en base a la cantidad de superficie virtual que la capital francesa requería para satisfacer los consumos de sus habitantes (foodprint). Igualmente hacen notar una presión sobre las regiones más próximas a la capital que debían intensificar su superficie para exportar alimentos y combustibles. Al parecer, la ciudad de Sevilla y el comercio de ultramar presionaban sobre los recursos de los municipios aledaños para satisfacer unos consumos en la capital que, con la superficie disponible, a bien seguro, no podían atender.

\subsection{La mayor concentración de olivos en el sur de España}

El formidable nivel de expansión agrícola que tenían ciertas zonas del Aljarafe, especialmente aquellas más cercanas a la capital, revelaba, en gran 
modo, una especialización en cultivos leñosos. Principalmente, en el cultivo del olivo.

La comarca tenía en total un $18 \%$ de su superficie productiva plantada con este cultivo, donde destacaba, claro está, la zona del Aljarafe 1 en la que se alcanzaba el 37\% de la superficie total. Es cierto que este porcentaje se vería en algunas otras partes de Andalucía como, por ejemplo, en la sierra norte de la provincia de Jaén ${ }^{6}$ o la comarca de Estepa (Caballero, 2004). Pero más difícil era encontrar en cualquier punto del Mediterráneo municipios que, como Mairena del Aljarafe, el olivar ocupaba un $85 \%$ de su término. De las docenas de trabajos sobre usos del suelo que hemos revisado en ninguno de ellos encontramos una concentración arbórea tan prominente como la que existe en el Aljarafe.

En cualquier caso, lo que realmente constituye una disonancia paisajística no es tanto el volumen de la superficie de olivar sino la estructura de esta y la morfología de las plantaciones. El Catastro de Ensenada distingue entre diferentes categorías de cultivo que se correspondían con clases fiscales. Sabemos que el olivar se dividía entre tres o cuatro clases atendiendo, generalmente, a su productividad.

La primera calidad en el Aljarafe casi alcanzaba, según el Catastro de Ensenada, las 3.000 ha. Suponía un tercio de la superficie olivarera total. Por su parte, toda la provincia de Jaén contaba 38.000 ha plantadas con este cultivo de las cuales menos de 5.000 eran de primera (Sánchez, 1989). Esto es, en las apenas 100.000 ha de una pequeña comarca sevillana había casi el mismo número de olivos de primera calidad que en una provincia con más de un millón de hectáreas y que hoy es líder mundial en la producción de aceite. No es de extrañar que quien en busca de la etimología de la palabra Aljarafe deduzca que se habla de tierra plantada de olivos (Herrera, 1980). O que ciertos viajeros de la época, como Laborde, hablaran de esta parte de Andalucía por sus «espesos bosques (de olivar)» y sus «famosas aceitunas». La Europa preliberal vería nacer pequeños territorios que desarrollaron una suerte de protocapitalismo en base a la especialización en cultivos leñosos.

6 En la reconstrucción de la superficie de olivar de la provincia de Jaén realizado por Sánchez (1989) es posible encontrar municipios con una alta densidad de olivares, como Andújar, que se ubicaban en la zona noroeste de la provincia, cerca del paso de Despeñaperros que conectaba con el centro del país. 
Figura 1. Superficie cultivada en la comarca del Aljarafe en 1750 (\% sobre la SAU).

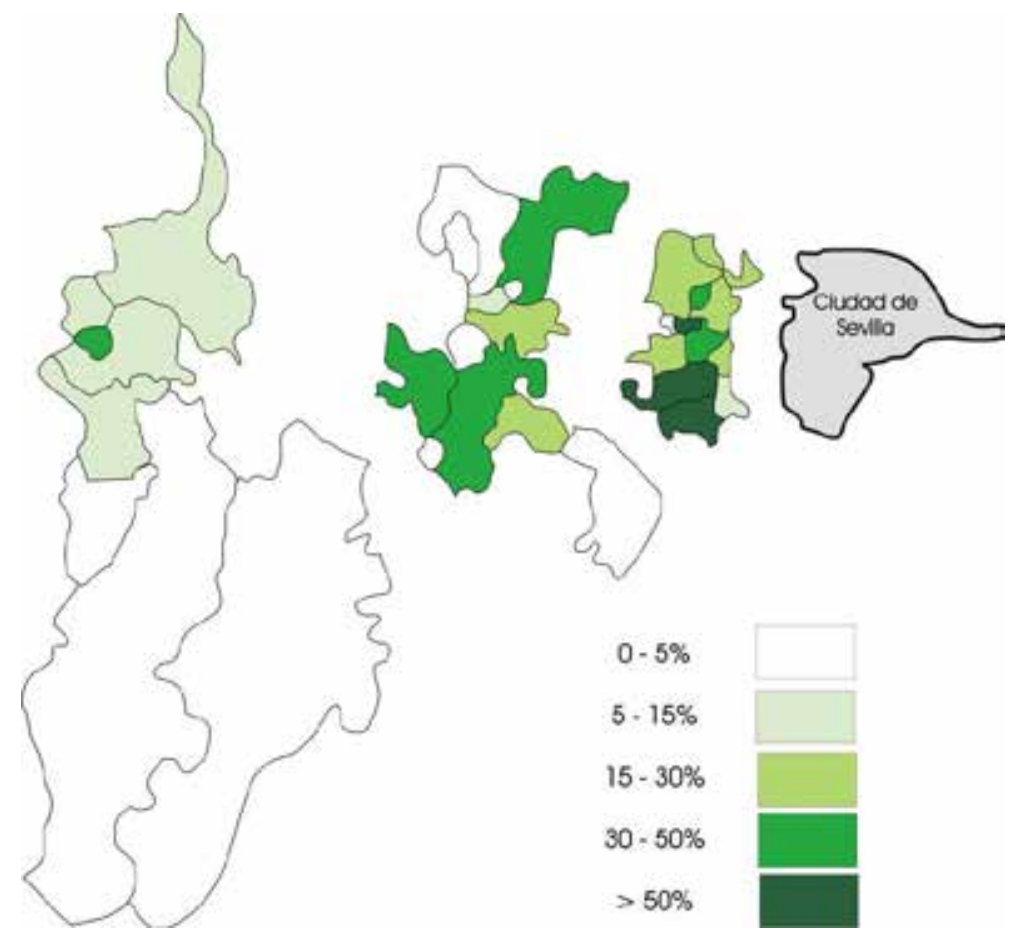

Fuente: elaboración propia.

\section{El OLIVAR, EN LAS AGRICULTURAS DE CAMPIÑA}

Los niveles de expansión agrícola y densidad poblacional que muestra el Aljarafe estaban lejos de ser representativos de agricultura andaluza de mediados del siglo XVIII. Recordemos que la densidad de población andaluza a finales de ese siglo apenas superaba los $20 \mathrm{hab} / \mathrm{km}^{2}$, la superficie cultivada no alcanzaba el $50 \%$ y, de esta, buena parte se aprovechaba con rotaciones poco intensivas donde abundaban los años de barbecho.

El municipio de Baena, propio de la campiña andaluza en la provincia de Córdoba, respondería al canon historiográfico andaluz relatado en las influyentes obras de Michel Drain, Antonio M. Bernal, H. Ponsot o Josefina Cruz Villalón. Baena cultivaba ya en 1753 más del 85\% de su superficie agraria útil. Un nivel de extensión agrícola digno de atención. Aún así, mantenía una reserva de unas 5.000 hectáreas dedicadas al pasto o a los usos 
forestales. Entre ellas, algunas dehesas potriles del común 7 . La mayor parte de su superficie estaba destinada al cultivo del cereal como ocurría en el resto de Andalucía pero con un porcentaje claramente superior (recordemos que la media de la región rondaba el 55\% de la superficie total). Más sorprende la formidable extensión del olivar y la viña. El primero ocupaba, según las Respuestas Generales, cerca de 5.000 hectáreas y repercutía en más de un $10 \%$ de la SAU. Aparentemente Baena fue municipio prematuros en la especialización leñosa andaluza y uno territorio de gran concentración olivarera si lo comparamos con otras zonas de la región (Sánchez, 1989). La corta distancia con respecto a los puertos de Málaga y Sevilla justifica este hecho ${ }^{8}$. Ser frontera de las Sierras Subbéticas también?. Sin olvidar la relativa cercanía al paso de Despeñaperros ${ }^{10}$. Dicho de otra manera, la ubicación del lugar creaba un marco oportuno para quebrar las limitaciones sobre el transporte que pesaban sobre las agriculturas preindustriales.

El proceso de roturación preliberal en Andalucía tuvo en este lugar un testigo de excepción. En la segunda mitad del siglo XVIII los repartimientos de tierras y las roturas fueron una constante ${ }^{11}$. Los bienes concejiles, aún así, seguían teniendo un peso importante: superaban las 5.500 hectáreas aunque casi la mitad de ellos se destinaban al arrendamiento para el cultivo del cereal en régimen de «año y vez» ${ }^{12}$ el resto, más de 3000 ha, seguían teniendo usos silvopastoriles.

7 En la respuesta 23 de las Respuestas Generales del Catastro del Marqués de la Ensenada. AMB, Legajo 1, Catastro del Marqués de la Ensenada, «Respuestas Generales, 1753».

8 En muchas de las respuestas al interrogatorio hecho por el Ministerio de Fomento sobre la Crisis Agrícola y Pecuaria se apunta que las zonas aledañas a Baena conducían su aceite al puerto de Málaga para la exportación. Este documento se cita como MF (1887/89). Ver la respuesta realizada por la «Real Sociedad Económica de Amigos el País de Baena», tomo 3 , respuesta 158, página 155 y siguientes. Se apunta que la exportación se destina «al puerto de Málaga».

9 En Martín (2003) se demuestra cómo Baena vendía pequeñas cantidades de aceite a localidades de la Sierra Sur como Alcalá en los siglos XVII y XVIII que, por entonces, no eran capaces de autoabastecerse.

10 Hernández (2007) ha documentado importaciones de aceite de oliva para satisfacer la demanda de la industria textil en Castilla. Según sus datos la mayor parte provenía de la provincia de Córdoba.

11 En el AMB, en la sección de agricultura, se amontonan legajos sobre repartimentos de tierra en el siglo XVIII que aún están descatalogados. Sobre este proceso consúltese (Horcas, 1990).

12 En la respuesta 23 de las Respuestas Generales del Catastro del Marqués de la Ensenada. AMB, Legajo 1, Catastro del Marqués de la Ensenada, «Respuestas Generales, 1753». Y, también, a lo largo de las Respuestas Generales de la misma fuente: AMB, Legajos 1-10, Catastro del Marqués de la Ensenada, «Respuestas Particulares, 1753». 
El nivel de colonización agrícola era sumamente importante y su especialización leñosa relativa también. Pero no debemos de olvidar el hecho de que el $80 \%$ de la superficie cereal se regía con la rotación de «al tercio», con dos años de descanso. Baena, con una densidad de población de 20 $\mathrm{hab} / \mathrm{km}^{2}$, también estaba «vacía». Y el aparentemente extraordinario plantío de leñosos no era tal cosa si escudriñamos las fuentes con más detenimiento.

Cuadro 3. Datos sobre población, usos del suelo y cabaña ganadera en Baena , 1753.

\begin{tabular}{|c|c|c|}
\hline Población & [ha] & 8.000 \\
\hline Densidad de Población & [ha/ & 20,52 \\
\hline $\begin{array}{l}\text { Superficie disponible por } \\
\text { habitante }\end{array}$ & [ha] & 4,87 \\
\hline Herbáceos & [ha] & 25.995 \\
\hline Hortofrutícola & [ha] & 165 \\
\hline Viña & [ha] & 4.898 \\
\hline Olivar & [ha] & 1.837 \\
\hline Cultivado (1) & [ha] & 32.895 \\
\hline Pastos (2) & [ha] & 3.142 \\
\hline Monte (3) & [ha] & 2.039 \\
\hline Superficie Agraria Útil $(1+2+3)$ & [ha] & 38.076 \\
\hline Inútil & [ha] & 918 \\
\hline Total & [ha] & 38.993 \\
\hline
\end{tabular}




\begin{tabular}{|l|r|r|}
\hline Asnal & {$\left[\mathrm{n}^{\circ}\right]$} & 1.860 \\
Caballar & {$\left[\mathrm{n}^{\circ}\right]$} & 551 \\
Mular & {$\left[\mathrm{n}^{\circ}\right]$} & 237 \\
Vacuno & {$\left[\mathrm{n}^{\circ}\right]$} & 2.662 \\
Cabezas Labor & {$\left[\mathrm{n}^{\circ}\right]$} & 5.310 \\
Cerdal & {$\left[\mathrm{n}^{\circ}\right]$} & 4.368 \\
Caprino & {$\left[\mathrm{n}^{\circ}\right]$} & 828 \\
Ovino & {$\left[\mathrm{n}^{\circ}\right]$} & 14.129 \\
Cabezas Renta & {$\left[\mathrm{n}^{\circ}\right]$} & 19.325 \\
Total Cabezas & {$\left[\mathrm{n}^{\circ}\right]$} & 24.635 \\
\hline
\end{tabular}

Fuente: Catastro del Marqués de la Ensenada, Baena, 1753. AMB, Legajos 1-10.

Encontramos una importante superficie de olivar según las Respuestas Generales del Catastro de 1753. En concreto, la superficie del cultivo se acercaba a las 5.000 ha, un $12 \%$ de la superficie total y un $18 \%$ de la superficie cultivada. Sin embargo, al introducir los datos a través de las Respuestas Particulares, esto es, atendiendo a las propiedades que cada vecino justificaba, la dimensión del cultivo resultante es mucho menor. Solo se contabilizaban unas 1.200 ha. No descartamos la ocultación fiscal como explicación a tal fenómeno pero la propia fuente aporta una respuesta más elocuente. Además de las clases fiscales, las Respuestas Particulares del Catastro de Baena incluían otra taxonomía para cultivo del olivo, a saber: distinguían si este se extendía «en líneas derechas» o de forma «dispersa». El texto describe bien a qué se refería este fenómeno de ordenar los olivos de forma «dispersa»: quedaban insertos dentro de hazas de cereal, huertas o zonas de dehesa con una baja densidad de plantación e integrados con otros cultivos. Representaba una arboleda sin orden dentro de los campos de cereal, las huertas o los pastizales del lugar. Un olivo que podíamos llamar 
«adehesado», «campal», de baja intensidad y menores labores, dibujaba buena parte del paisaje agrario de campiña ${ }^{13}$.

El imaginario colectivo que identifica nuestros olivos como un cultivo ordenado, comercial y propio de la modernización agraria parece quedar en entredicho. El olivar, en Baena, quedaba dentro un complejo agroecosistema donde convivían la producción de trigo y cebada, las cubiertas espontáneas, la producción de aceitunas, de ramón o de madera con la ganadería. Una agricultura «promiscua» utilizando la descripción que a finales del XVIII hiciera Landeschi para la Toscana italiana.

Siguiendo las huellas de esta particular forma de ordenar los olivares hemos revisado los contratos de arrendamiento de los Protocolos Notariales de Baena para el período comprendido entre 1743 y 1763. En esta fuente se detallan los elementos de la finca arrendada así como los manejos que el arrendador habrá de ejecutar durante el tiempo de duración del contrato lo que aporta una descripción del paisaje agrario a mediados del XVIII que ayudará a corroborar nuestra hipótesis. En las decenas de legajos consultados es un lugar común encontrar contratos que, como el que Franscisco Hermosilla firmara contra Antonio de Priego en 1751, quede arrendada una finca que «consta de cuarenta fanegas de tierra en que bay olivar, chaparraly tierra calma». Y otra del mismo año de «once celemines de tierra con diez, olivos». Tampoco faltan otros de «tierra calma y de riego» con estacas de olivar. O huertas «suelo y sus árboles y tres celemines de tierra plantados de estacas contiguos». O contratos en el que se arriendan solo «dos hazas de cereal» pero donde más adelante se avisa sobre los «veintinueve olivos» que se levantan en las mismas. Y un largo etcétera... ${ }^{14}$

13 Esta tipología de paisaje olivarero ya fue puesta de manifiesto por Ester Calderón (2002) cuando describió los manejos históricos del olivar en diversos estudios de caso de la comarca de «Los Montes Orientales» en la provincia de Granada. En este trabajo, se revela, de manera inédita en la literatura sobre la historia del olivar, que este cultivo lejos de aparecer con la morfología actual se presentaba como un árbol, como ella misma catalogó, de tipo «frutal» por su disposición o «campesino» $\mathrm{y}$ «de subsistencia» por su gestión.

14 Los ejemplos son numerosos. Todos en el AHPC. Leg. 469. Escribanía de Pedro B. Gameri. «Don Faustino de Jerenas, presbítero. Arrendamiento contra Sebastián de Jeremas», 1751: «Un haza de fanega y media de tierra calma en el sitio de Pedro Muñoz y tres obradas de olivar en el partido que llaman del Despeñadero». Leg. 469. Escribanía de Pedro B. Gameri. «Don Francisco Claudio. Arrendamiento y Carta de Pago contra Diego Cañete». 1751: «Once celemines de tierra con diez olivos». Leg. 469. Escribanía de Pedro B. Gameri. «Francisco Trujillo y Hermosilla arrendamiento contra Antonio de Priego y Luis Cabeza». 1751: "Casería que el susodicho tiene que dicen de Pedro Baena de este término que consta de cuarenta fanegas de tierra en que bay olivar, 
El paisaje olivarero del XVIII distaba mucho del cultivo que hoy puebla nuestros campos. Incluso aquellos olivares ordenados «en líneas derechas» contaban un marco de plantación muy inferior al actual (entonces apenas llegaba a los 90 pies por hectárea). Las calles entre olivos eran más anchas y era común encontrar cereal o leguminosas en las mismas. Como veremos más adelante los manejos poco intensivos de los mismos permitían espesas cubiertas que convivían entre cultivos y cabezas de ganado.

Entendemos ahora el desencuentro entre las cifras aportadas por las Respuestas Generales y las Respuestas Particulares en el Catastro. Cuando a un propietario se le preguntaba por la extensión de sus tierras, este apuntaba que «tenía una parcela de cereal de una hectárea con 7 olivos sueltos que, juntos ellos, ocuparían 0,2 ha» ${ }^{15}$. Las respuestas particulares solo tomaban en consideración la superficie efectiva de cada árbol no el conjunto de la parcela. Además de esto, las Respuestas Generales apuntan una superficie de unas 5.000 ha de olivar de las cuales más de 3.500 ha se corresponden con la tercera calidad. En Baena, la tercera calidad de olivar, arrojaba rendimientos ocho veces inferiores a la primera o lo que es lo mismo: la tercera de olivar, que era la mayoría, tomaba nota de aquellas explotaciones donde el cultivo del olivo convivía con chaparros, cereal, cubiertas y ganado. Esta revelación entendemos que tiene importancia a la hora de acercarnos a la historia del olivar. Sobre todo a la hora de tomar con cautela las cifras de su superficie con las que habitualmente trabajamos. Decenas de trabajos, imposible citarlos todos aquí, han reconstruido la superficie de olivar para sus estudios

chaparral y tierra calma». Leg. 469. Escribanía de Pedro B. Gameri. «Don Francisco María del Portillo arrendamiento contra Fernando Melindo y su Mujer», 1749: Arrendamiento de una «heredad y tierra calma y de riego» que más adelante apunta que tiene estacas de olivar. Leg. 473. Escribano Pedro B. Gámez. 1755-56. «Don Juan Agustín Luna. Arrendamiento contra Juan de Tienda y Arca». 1756: que arrienda una huerta con estacas de olivos Leg. 473. Escribano Pedro B. Gámez. 1755-56. «Alberto Andrés Carro contra Francisco Moreno», 1755: que tiene un haza con 29 olivos. Esta fuente recoge, obviamente, aquellos arrendamientos de olivares intensivos, no solo frutales. Por ejemplo: «22 obradas y media de olivar propias de las propias de las Capellanías que administra don Pedro». Por 3 años.

15 Para aclarar la cuestión. En las Respuestas Particulares del Catastro cuando cada propietario era interrogado sobre sus pertenencias, era posible encontrar respuestas sobre sus olivares como la siguiente: «Otra pieza de tierra plantada de olivar disperso en el pago de la Sierra $(. .$.$) de cabida de once celemines (...)». O bien: «Otra pieza de olivar en líneas$ derechas en el pago de las Cotillas». Sin embargo, era muy común que la respuesta fuera: «Una pieza de tierra en el pago del Cascajar distante de esta pueblo un cuarto de legua de cabida de dos fanegas y nueve celemines seis de ellos ocupan treinta olivos que se hayan dispersos en dicha pieza». AMB, Legajo 5, página 112, Catastro del Marqués de la Ensenada, «Respuestas Particulares. Propiedades de Eusebio Ambrosio de Luque, 1753». 
de caso atendiendo a los datos de las Respuestas Generales del Catastro de Ensenada. Sin embargo, a través del detalle cuantitativo y cualitativo de las Respuestas Particulares de la misma documentación es posible encontrar que la superficie efectiva del cultivo puede ser, como ocurre en Baena, hasta cinco veces menor. Todo ello derivado la particular disposición de su plantío que, lejos de ser ordenado, aparecía disperso y conjugado con otros aprovechamientos.

\section{El Olivar, EN LAS AGRICULTURAS DE SIERRA}

Este fenómeno, entendemos que debe acusarse en aquella otra gran entidad geográfica andaluza como es el caso de las zonas de sierra. Para su estudio tomamos el caso del municipio granadino de Montefrío, en la comarca de Los Montes Orientales.

Montefrío, como cabe esperar, superaba la media andaluza de superficie silvopastoral. En concreto, casi un 70\% del término tenía usos de pasto o monte. Apenas una tercera parte de su superficie quedaba sembrada de cereal y leguminosas de las que casi la totalidad se trabajaban «al tercio». La extensión de cultivos leñosos como la vid y el olivar era testimonial (no llegaba al 1\% de la SAU). Los años centrales del siglo XVIII dibujan en este pueblo un caso paradigmático de economía de sustento. Montefrío, en 1752, era un municipio realengo donde la gran propiedad estaba en manos de la nobleza pero la baja densidad de población permitía que las poco más de 1.000 familias que habitaban el pueblo hubieran accedido a la propiedad sin mayores problemas y manejaran los recursos mediante un proceso de integración agroganadera paradigmática. De hecho, unas 10.000 hectáreas, casi la mitad del municipio, se catalogaban en el Catastro de Ensenada como rotación «al tercio» de muy mala calidad. Este hecho, como ya había apuntado Manuel Martínez (1995), se debía a que, en realidad, estábamos ante dehesas pastoreables en las que se sembraban manchones de cereal de forma muy selectiva y con bajísima intensidad ${ }^{16}$.

16 Esta interpretación nos ha forzado a incluir esas hectáreas en la categoría de «pastos» y no en la de cultivos «herbáceos». Eso y también el hecho de que las Respuestas Generales del Catastro de 1752 explicite abiertamente que la superficie de cereal de peor calidad apenas produce y se destina con mayor profusión al pasto. AMM, Legajo: Catastro del Marqués de la Ensenada, «Respuestas Generales, 1752». 
En las agriculturas orgánicas no solo convivían en equilibrio el agersaltus-silva sino que mediante prácticas comunitarias preliberales como la derrota de mieses «la distinción entre los terrenos de labranza y de pasto era a menudo muy vaga» (Vassberg, 1986, p. 197). Tal es el caso que presenciamos. De esta manera, la superficie destinada usos silvícolas o pastoriles por habitante en Montefrío era cinco veces superior a la de Baena (3,30 ha/ hab por $0,65 \mathrm{ha} / \mathrm{hab}$ respectivamente). Aunque ambos pueblos contaban con la misma densidad de población el primero de ellos, sito en la serranía granadina, ejercitó una vocación ganadera principalmente hacia la cabaña de renta. Este aislado municipio no requería una fuerte intensificación agraria toda vez que podía completar su sustento con cultivos de baja intensidad, vagas superficies hortofrutícolas y leñosas y, sobre todo, con miles de cabezas caprinas y ovinas que podían pastar en los matorrales del lugar así como en los barbechos (ver tabla 1.2). El bosque mediterráneo también proveía sobradamente de combustibles y maderas a una población que no establecería fluidos nexos comerciales hasta mediados del siglo XX.

Un paisaje que resume un «arreglo territorial» propio de las economías orgánicas de baja intensidad. Montefrío, habida cuenta de su particularidad geográfica y orográfica estaba abocado al aislamiento. Todo lo cual hacía de este pueblo una paradigmática «isla de escasez» (Sieferle, 2001) en la cual debía garantizarse el abastecimiento de la mayoría de productos de sustento. Dicho lo cual, entendemos que la superficie de olivar ocupara un espacio tan escaso. Sin embargo, no interesa saber si la disposición de su plantío también revela una pauta análoga a la de los olivares dispersos de Baena.

\section{Cuadro 4. Datos sobre población, usos del suelo y cabaña ganadera en Montefrío en 1752.}

\begin{tabular}{|c|c|c|}
\hline Población & $\begin{array}{c}{[\mathrm{ha}]} \\
\text { Densidad de Población }\end{array}$ & $\begin{array}{c}5.108 \\
{[\mathrm{ha} /}\end{array}$ \\
$\begin{array}{l}\left.\mathrm{km}^{2}\right] \\
\text { Superficie disponible por } \\
\text { habitante }\end{array}$ & \begin{tabular}{c} 
[ha] \\
\hline
\end{tabular} & 5 \\
\hline
\end{tabular}




\begin{tabular}{|l|c|c|}
\hline Herbáceos & {$[\mathrm{ha}]$} & 7.372 \\
Hortofrutícola & {$[\mathrm{ha}]$} & 71 \\
Viña & {$[\mathrm{ha}]$} & 118 \\
Olivar & {$[\mathrm{ha}]$} & 58 \\
Cultivado (1) & {$[\mathrm{ha}]$} & 7.619 \\
Pastos (2) & {$[\mathrm{ha}]$} & 13.048 \\
Monte (3) & {$[\mathrm{ha}]$} & 3.809 \\
Superficie Agraria Útil $(1+2+3)$ & {$[\mathrm{ha}]$} & 24.477 \\
Inútil & {$[\mathrm{ha}]$} & 1.061 \\
Total & {$[\mathrm{ha}]$} & 25.537 \\
\hline Asnal & {$\left[\mathrm{n}^{\circ}\right]$} & 913 \\
Caballar & {$\left[\mathrm{n}^{\circ}\right]$} & 226 \\
Mular & {$\left[\mathrm{n}^{\circ}\right]$} & 64 \\
Vacuno & {$\left[\mathrm{n}^{\circ}\right]$} & 1.776 \\
Cabezas Labor & {$\left[\mathrm{n}^{\circ}\right]$} & 2.979 \\
Cerdal & {$\left[\mathrm{n}^{\circ}\right]$} & 6.860 \\
Caprino & {$\left[\mathrm{n}^{\circ}\right]$} & 14.565 \\
Ovino & {$\left[\mathrm{n}^{\circ}\right]$} & 21.322 \\
Cabezas Renta & 42.747 \\
Total Cabezas & 45.726 \\
\hline
\end{tabular}

Fuente: Catastro del Marqués de la Ensenada, Montefrío, 1752. AMM. 
La pregunta número 8 de las Respuestas Generales del Catastro quiere informarse sobre la ordenación del plantío en la villa. En Montefrío, se responde que los árboles se pueden encontrar en unos lugares «en bileras y en sus márgenes» mientras que «en otras se hallan esparcidos y repartidos en todas ellas, sin regla». Una pauta similar a la observada en Baena. Sin embargo, en la respuesta a la pregunta número 13 sobre «productos arbóreos»los informantes del pueblo son mucho más explícitos:

«Los olivos que hay en este dicho término, son en su especie de las mismas cuatro calidades que la tierra donde se hallan (...). Están que es lo más, esparcidos y más claros, por la poca sustancia de la tierra (...). Y en esta forma dicho habrá dos mil olivos vitales pocos más o menos en dicho término, que componen en su extensión si estuvieran todos juntos en un pago y bajo de una cuerda a noventa fanegas de tierra».

La respuesta es categórica. El plantío del olivar en este momento de su historia lejos de ordenarse en el territorio en líneas perfectas ajeno a usos alternativos se abría paso entre las diferentes tierras de pasto y cereal que componían las teselas paisajísticas del monte mediterráneo. Así pues, las noventa fanegas de olivar del pueblo solo son tal cosa si, como en Baena, uniéramos la superficie equivalente de sus olivares a lo largo de todo el municipio.

Aunque resulta más difícil encontrar arrendamientos de olivar en lugar donde apenas se había desarrollado este cultivo (recordemos que Montefrío contaba solo con unas $100 \mathrm{ha}$ ). Una búsqueda selectiva a través de los contratos de arrendamiento comprendidos entre 1744-1761 de los Protocolos Notariales nos ayuda a confirmar la hipótesis de un plantío disperso e integrado con otros elementos de su complejo agroecosistema.

Así las cosas, los pies de olivo aparecían junto con otros frutales en zonas de cereal poco intensivo: se arriendan «dos fanegas de tierra con diferentes pies de olivos y moral en el pago del Reahi. En las mismas zonas pero sin otros frutales: una «fanega de tierra de labor con algunos olivos en partido de Valle Hermoso». O con el olivo más presente: «un haza de fanega y media de tierra poblada de olivos que tiene el partido que llaman del Legido». También lo vemos inserto en aquellas explotaciones donde los herbáceos se cultivaban de una manera más intensiva como es el caso del ruedo en el contrato de «dos hazas de tierra calma de labor con diferentes olivos en el término y ruedo» o en este otro de «un haza de trece celemines de tierra de labor con siete olivos (...) en el ruedo de esta villa». Finalmente, 
este frutal disperso, propio del secano andaluz, se alzaba entre parcelas de regadío como en una «buerta con sus frutales, olivos, álamos y moreras» ${ }^{17}$.

\section{Discusión de los Resultados}

\section{Una tipología de los paisajes olivareros preindustriales.}

La evidencia de los documentos estudiados nos permite practicar una taxonomía de los paisajes históricos del olivar y su ecología. De un lado prevalece el «olivar monocultural» propio del Aljarafe sevillano y de aquellas zonas anejas a los puertos o principales corredores comerciales del momento. Es un olivar plantado en líneas derechas, domesticado «ex profeso» para un mejor control de las labores y una orientación mercantil (todo esto lo detallaremos más adelante).

Los paisajes olivareros de Baena, en el XVIII, nos cuentan una historia de un «olivar mercantil y ordenado» que aún era minoría en el municipio. De hecho los de primera calidad de olivar -aquellos más productivos y ordenados-, solo ocupaban 60 ha: el 18\% de la superficie olivarera y tan solo el 1\% de la superficie total del municipio. Así pues, en zonas de campiña como Baena esta forma paisajística convivirá con nuestra segunda categoría: el «olivar adehesado». Este será protagonista en su expansión por los montes andaluces y convivirá con el intensivo o «monocultural» en las zonas de valle e incipiente vocación mercantil donde será posible derivar los usos del suelo hacia cultivos que no eran de sustento. El «olivar adehesado» queda integrado en explotaciones de cereal, huertas e incluso dehesas como un frutal más del que obtener leña, ramón, aceitunas, etc. (ver simulación en la figura 2).

17 Todos estos casos y otros más en: AHPNG: Legajo: Montefrío, 1756-1759. Notaría de Sabario Isidoro Rufo. Tomo único. Contrato de arrendamiento: «1757. Francisco M. Luján, arrendamiento contra Juan de la Peña Cuevas». Págs., 715-717. AHPNG: Legajo: Montefrío, 1758-1761. Notaría de Diego Manuel García y Contreras y otros. Tomo único. Contrato de arrendamiento: «1761. Miguel Rodríguez de la Peña, arrendamiento contra Pedro Miguel Hurtado». Legajo: Montefrío, 1747-1750. Notaría de Francisco Díaz de Otazu. Tomo único. Testamento: «1748. Ana de Castellanos, su testamento». Legajo: Montefrío, 17581761. Notaría de Diego Manuel García y Contreras y otros. Tomo único. Contrato de arrendamiento: «1758. Aranday Ramos de Azanda, arrendamiento contra Alonso Gordo Castellanos». Legajo: Montefrío, 1756-1759. Notaría de Sabario Isidoro Rufo. Tomo único. Contrato de arrendamiento: «1758. Francisca de Ordóñez, arrendamiento contra Salvador de Lorca». 
Figura 2. Simulación de los paisajes históricos de «olivar disperso» o «campesino» (a) y simulación de los paisajes históricos de «olivar monocultural» (b).

a)

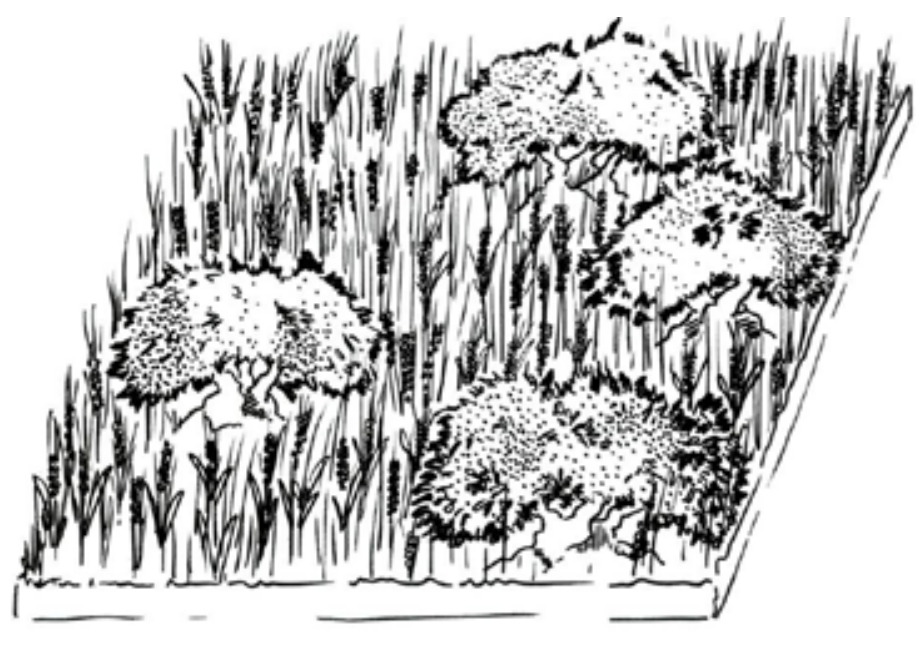

b)

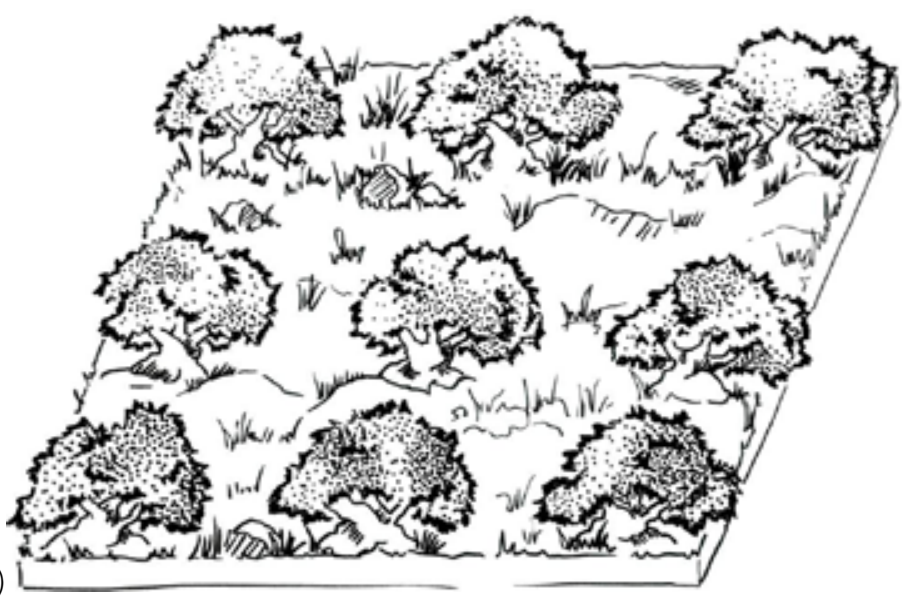

Fuente: dibujo de Paloma Serrano Castro.

El Antiguo Régimen en Andalucía retrata un país vacío donde la intensificación agraria solo se manifestaba en lugares muy específicos. Los paisajes describen una realidad a caballo entre los ecosistemas mediterráneos tradicionales y la vocación al monocultivo propia de las últimas décadas. A 
caso estamos presenciando un momento de transición de una agricultura que integraba sus usos agrícolas, ganaderos y forestales hacia otra que los desvinculaba fomentando una producción de bienes de mercado en un paisaje que ordenaba sus usos del suelo como compartimentos estancos. Un momento en el que convivían los «traditional landscapes», al decir de Antrop (2005), con los que habrían de llegar en las revoluciones decimonónicas y que terminarían por homogenizar el paisaje. Este «olivar disperso» que aparece habitualmente en los documentos de finales del Antiguo Régimen no sorprendería a buenos conocedores de la ecología de los paisajes mediterráneos. González Bernáldez (1981) ya nos avisaba de que «la dehesa y el olivar representan paisajes derivables del bosque mediterráneo por un aumento del control humano, representando zonas de madurez intermedia entre el bosque y el ager cerealista». La historiografía italiana ha caracterizado en la misma dirección los paisajes olivareros del Mezzogiorno que previos al proceso industrial y su vocación hacia el monocultivo el «albero di Minverva» se abrió paso en un proceso de domesticación de antiguos bosques (Bevilaqcua, 1989) hacia una ordenación más formal. De hecho, muy en consonancia con lo que estamos contando aquí, los últimos estudios sobre el origen genético del olivar apuntan a que en buena medida este se derivó de su variedad silvestre, esto es, de los acebuches (Besnard y Bervillé, 2000; Besnard et al, 2001).

Friedirch Ratzel apunta con tino que «en el espacio leemos el tiempo» ${ }^{18}$. Dicho de otro modo: el paisaje puede entenderse «como información organizada». Si miramos con atención los campos andaluces en pleno siglo XXI es posible, también, leer su historia. Una historia escrita hace varios siglos. O milenios. Un paseo por los campos de olivar del Aljarafe sevillano nos revelan árboles hoy dedicados al mercado internacional de la exportación de aceitunas de mesa pero que antaño fueron acebuches aún no domesticados para la producción olivarera. En Italia buena parte de la expansión olivarera se hizo en base a injertos de antiguos «olivastri ${ }^{19}$. Es más, un famoso tratado de agricultura toscano

18 Citado en Schlögel (2007, p. 14)

19 «Esso cresceva spontaneo allo stato selvatico un po» ovunque. Sulle basse 
de 1770 recomendaba, antes que plantar variedades productivas de olivar, seguir injertando antiguos acebuches con variedades nuevas porque aquéllos resultaban mucho más resistentes a las inclemencias meteorológicas toda vez que se habían adaptado durante milenios a los ecosistemas mediterráneos (Landeschi, 1770).

Figura 3. Antiguo acebuche injertado en variedades de olivar (Olivares, Aljarafe).

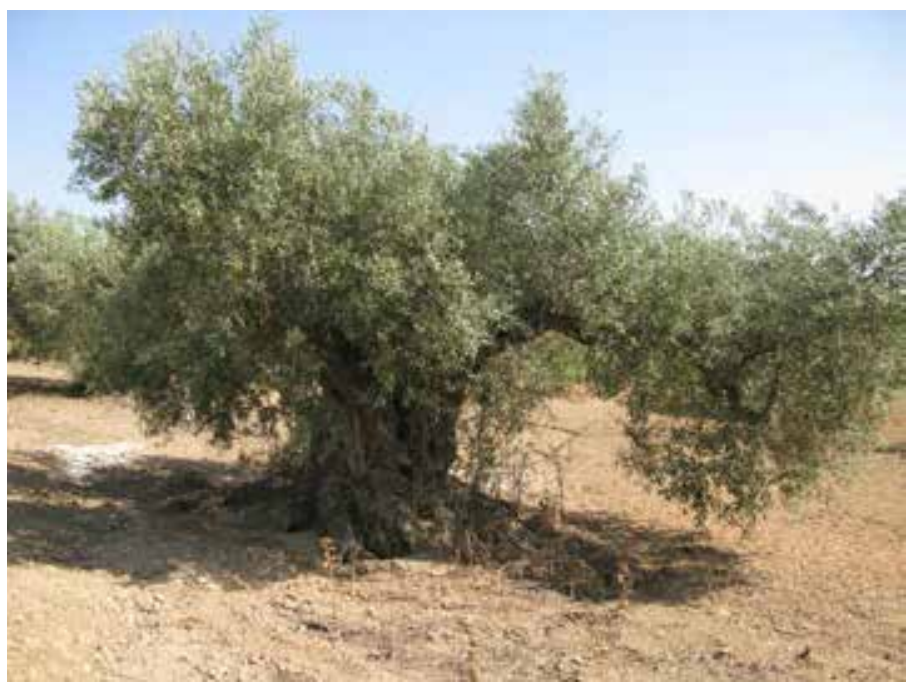

Fuente: elaboración propia.

Figura 4. Antiguos olivos entre cultivos de cereal (Montefrío).

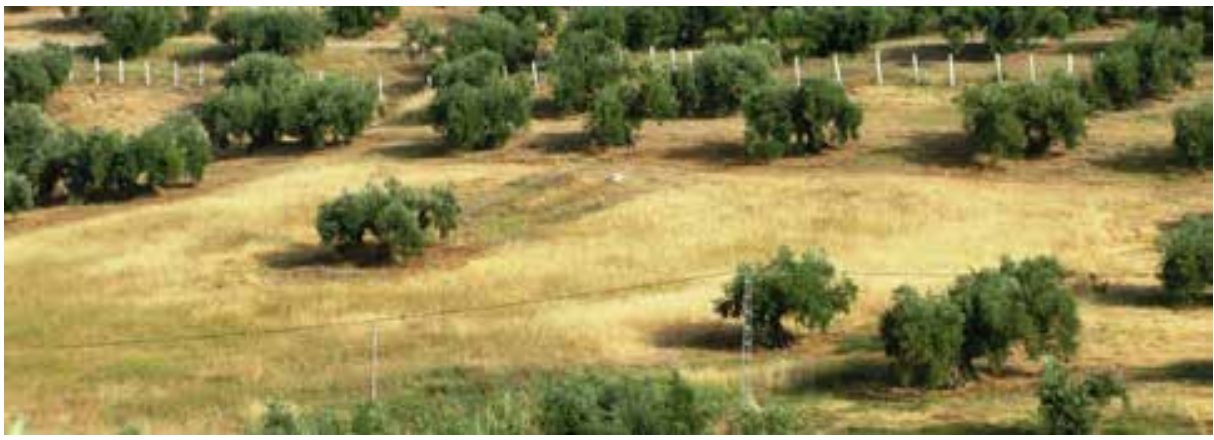

Fuente: elaboración propia.

colline o in pianura, fra le altre essenze della macchia mediterranea la dove dense selve di olivastri segnavano il paesaggio la pratica degli innesti sul ceppo selvatico dava vita ad oliveti produttivi» (Bevilacqua, 1989, p. 653). 
En los campos de Montefrío (ver figura 4) es posible encontrar antiguos restos de un «olivar disperso» entre zonas cereal con claro desconcierto y que hoy representa el vestigio de un tiempo pasado a modo de «palimpsesto cultivado». El olivar empieza a levantarse no como un árbol homogéneo, en hileras, con vocación mercantil, propio de la modernidad... fue la pausada antropización del bosque mediterráneo la que levantó los olivos hasta llegar al estadio final del monocultivo que, por lo visto hasta aquí, seguía siendo una excepción incluso en los principales productores de aceite.

\section{Algunas hipótesis y evidencias de sobre las causas de la débil y dispersa ordenación de los olivares antes de la etapa industrial.}

Es un canon historiográfico aludir a la trilogía mediterránea del cereal, la vid y el olivar. Lo que podría llevarnos a pensar que este árbol estuviera ocupando el suelo andaluz desde el mundo antiguo en igualdad de condiciones que los campos de cereal. Aunque la literatura ha documentado sobradamente que la expansión oleícola no llegaría hasta finales del siglo XIX (Zambrana, 1987, 2006) es habitual encontrar mitificaciones de los paisajes de la famosa tríada. Es cierto que olivares milenarios siguen en hoy pie $^{20}$ como ejemplo de su existencia remota y su importancia en el mundo clásico. No en vano su domesticación data de hace varios miles de años (Besnard y Bervillé, 2000; Besnard et al, 2001; Zohary y Hopf, 1994). Sin embargo, resulta inverosímil sostener que el monocultivo olivarero fuera una realidad antes del XIX. Esta afirmación solo puede sostenerse mediante una «tradición inventada» en base al testimonio de viajeros o escribanos antiguos que, al visitar España, se sorprendían con las masas de olivar que poblaban Andalucía. Así las cosas, Laborde, en sus viajes por el sur del país, nos hablaba a principios del XIX de «espesos bosques de una expansión inmensa». Estas referencias han sido retomadas por muchos autores para sostener el mito de un olivar omnipresente en los campos andaluces. En mi opinión, algunas fanegas de olivar pueden parecer un «espeso bosque» para habitantes del mundo atlántico no familiarizados con este árbol pero lo cierto es que raramente alcanzó, y solo en zonas muy concretas, el 10\% de la superficie cultivada a mediados del XVIII (Sánchez, 1989).

20 Solo basta echar un vistazo en el catálogo que recoge los «olivos monumentales de España» para comprobar la longeva edad de muchos de ellos (Muñoz et al., 2004). 
En realidad, esta ordenación del territorio no debe sorprendernos en tanto que historiadores del mundo rural. Como ya apuntara Enric Tello (1999, p. 198) a propósito de la diversidad como rasgo definitorio de los paisajes mediterráneos: «en el pasado la complementariedad de los usos agrosilvopastorales ha sido un factor clave para su estabilidad y capacidad de sustentación». El paisaje del olivar era prominente, sin duda, en Baena y la campiña del Guadalquivir. Pero, la tipología de un cultivo ordenado, dependiente de input ajenos y con vocación mercantil era minoritaria hasta en las zonas de mayor pujanza oleícola en las décadas centrales del XVIII. Por qué no había olivos y por qué crecieron en puntos tan selectivos es una cuestión que puede explicarse fácilmente si recordamos el funcionamiento de las agriculturas orgánicas tradicionales según lo descrito más arriba. La restricción de una transporte dependiente de la fuerza animal coartaba la las posibilidades comerciales ejerciendo una suerte de «ley del hierro» que obligaba a los municipios de interior, representados como «islas de escasez» (Sieferle, 2001) a producir buena parte de los bienes necesarios para satisfacer las necesidades de sus pobladores. Esta ley era tanto más estricta en un territorio como Andalucía donde, aunque se ha mitificado la figura del Valle del Guadalquivir, las zonas montañosas ocupan más de dos terceras partes de su superficie (ERA, 1980). Inconveniente añadido es la escarpada zona de Sierra Morena que separa la región del resto del país. Estas restricciones han desconectado una parte importante de los municipios andaluces que, ante la imposibilidad de establecer fluidas relaciones comerciales, se vieron obligados a producir en su término todos aquellos bienes necesarios para el sustento de la población y que en agriculturas orgánicas solo podían obtenerse mediante la fotosíntesis. Esto es, mediante los productos que los aprovechamientos agrícolas podían aportar. Así pues, la consabida «integración agrosilvopastoril» no era una forma lúdica de organizar la agricultura y mucho menos respondía a un comportamiento absentista tal y como repetían los Ilustrados. Era la única forma de obtener todos los bienes que se precisaban: alimentos, materiales de construcción, forraje, combustibles, textiles, etc... En suma: el monocultivo olivarero era una imposibilidad biofísica toda vez que el hombre no puede alimentarse únicamente de aceite ${ }^{21}$ (Guzmán, 2007). Ante la dificultad para

21 Añadamos además, que buena parte de la agricultura andaluza se regía mediante una apropiación de los recursos de tipo silvopastoral en la que la provisión de grasas animales era, de hecho, abundante. Entendemos que ante la posibilidad de explotar masivamente la cabaña ganadera de renta el papel de la grasa vegetal era menos importante. 
importar alimentos en grandes cantidades, en la organización de los usos del suelo urgían más las zonas de cereal (que proveían hidratos de carbono determinantes para una dieta de subsistencia) y las zonas silvopastorales de las que obtener combustible y alimentación para el ganado ${ }^{22}$. El ganado, recordemos, además de proveer alimentos y otro tipo de materiales jugaba un papel básico en las agriculturas preindustriales en tanto en cuanto proporcionaba abono en un período en el que el manejo de la fertilidad del suelo era capital y, también, era capaz de metabolizar productos que para el hombre eran inservibles y, así, hacer de ellos bienes útiles (Krausmann, 2004, p. 756).

Consecuentemente, no es una rareza que, de los cultivos de la tríada mediterránea, el del olivo fuera el que menos tierra de nueva roturación ocupase $^{23}$. Este hecho es perfectamente contrastable gracias a la información aportada por el Catastro del Marqués de la Ensenada. Con él podemos observar cómo las zonas de mayor expansión olivarera quedaban sitas en el Valle del Guadalquivir. La fertilidad de sus tierras y su amable orografía habían atraído a la mayoría de la población andaluza del momento (ERA, 1980) y permitían con mayor facilidad establecer corredores comerciales que conectaran Cádiz con Sevilla y Córdoba y así, pasando por el norte de Jaén, cruzaban Despeñaperros hacia los mercados del interior (Ringrose, 1972).

El acceso al mar aparecía como una de las pocas vías para superar las limitaciones del transporte preindustrial (Bagwell, 1974; Smil, 2001). El olivo, tolera bien el frío, el calor, bajas dosis de abonado e incluso la sequía (Elías y Ruiz, 1977; Navarro y Parra, 2004). Pero no alcanza a tolerar la humedad marítima que afecta directamente a su reproducción. Se expandirá, así pues, lejos del influjo del mar (o de las zonas de vega). De esta manera, los alrededores de Sevilla, lugar portuario pero de interior, se erigiría como inmemorial territorio olivarero.

22 Una obra clásica de la historiografía agraria española rompía con este mito dibujando, de manera acertada, una agricultura decimonónica obligada a la "generalización de un policultivo que cubriera las necesidades de autoabastecimiento con predominio de cereales» (Garrabou y Sanz, 1985, p. 13).

23 De las roturaciones documentadas en el siglo XVIII en Andalucía el cereal representó más de 14 mil ha. La vid 2361 ha. El olivar, a la cola, sumaba 2045 ha (Sánchez, 1988, p. 68-69). 


\section{Abreviaturas de las fuentes archivísticas}

AHPC: Archivo Histórico Provincial de Córdoba.

AHPNG: Archivo Histórico de Protocolos Notariales de Granada.

AHPS: Archivo Histórico Provincial de Sevilla.

AMB: Archivo Municipal de Baena.

AMCC: Archivo Municipal de Castilleja de la Cuesta.

AMM: Archivo Municipal de Montefrío.

\section{Bibliografía}

ANES, G. (1999): Informes en el expediente de Ley Agraria: Andalucia y La Mancha, 1768. Madrid, Ministerio de Economía y Hacienda. Centro de Publicaciones.

ANGELS, S. (1999): «The changes in the olive-growing geography of Andalusia», Olivae, n. 78, 1999, p. 12-22.

ANTROP, M. (2005): «Why landscapes of the past are important for the future», Landscapes and Urban Plannig, n. 5-70, pp. 21-34.

BAGWELL, P.S. (1974): The Transport Revolution from 1770. London, Batsford, 1974.

BERNAL, A.M. (1979): La lucha por la tierra en la crisis del Antiguo Régimen. Madrid, Taurus.

BERNAL, A.M. y DRAIN, M. (1975): Les campagnes sevillaines aux XIXeXXe siècles. Paris, E. de Boccard.

BERNAL, A.M. y GARCÍA BAQUERO, A. (1976): Tres siglos del comercio sevillano, (1598-1869): cuestiones y problemas. Sevilla: Cámara Oficial de Comercio, Industria y Navegación. 
BESNARD, G. y BERVILLÉ, A. (2000): «Multiple origins for Mediterranean olive (Olea europea L. subsp. europea) based upon mitochodrial DNA polymorphisms», Comptes Rendus de l'Academie des Sciences, serie III, n. 323, p. 173-181.

BESNARD, G., BARADAT, P. BERVILLÉ, A. (2001): «Genetic relationships in the olive (Olea Europaea L.) reflect multilocal selection of cultivars», Theoretical and Applied Genetics, n. 102, p. 251-258.

BEVILAQUA, P. (1989): «Clima, mercato e paesaggio agrario nel mezzogiorno», en Bevilaqua, P. (ed.), Storia dell'agricultura italiana in etá contemporanea. Vol. I: Spazi e paesaggi. Venecia: Marsilio Editori, p. 643-676.

BILEEN, G., BARLES, S., GARNIER, J., ROUILLARD, J., BENOIT, P. (2009): «The food-print of Paris: long-term reconstruction of the nitrogen flows imported into the city from its rural hinterland», Regional Environmental Change, n. 9, p.13-24.

BOSERUP, E. (1984): Población y cambio tecnológico. Barcelona, Crítica.

CABALLERO, M. (2004): Historia del olivar en la comarca de Estepa. Sevilla, Consería de Agricultura, Pesca y Alimentación, Junta de Andalucía.

CRUZ VILLALÓN, J. (1980): Propiedady uso de la tierra en la Baja Andalucía. Carmona, siglos XVIII-XX. Madrid, Ministerio de Agricultura, Pesca y Alimentación.

CRUZ VILLALÓN, J. (1991); «Familia campesina y pequeña explotación en Andalucía», en Saavedra, P. y Villares, R. Señores y campesinos en la Peninsula Ibérica, siglos XVIII-XX, Vol. 2. Campesinado y pequeña explotación, p. 139-155.

CUSSÓ, X.; GARRABOU, R. y TELLO, E. (2006): «Social metabolism in an agrarian region of Catalonia (Spain) in 1860-1870: Flows, energy balance and land use», Ecological Economics, n. 58, p. 49-65.

ELÍAS, F. y RUIZ, L. (1977): Agroclimatología de España. Madrid, Ministerio de Agricultura.

ERA, GRUPO DE ESTUDIOS RURALES ANDALUCES (eds.) (1980): Las agriculturas andaluzas. Madrid, Ministerio de Agricultura, Pesca y Alimentación. 
FISCHER-KOWALSKI, M., HABERL, H. y KRAUSMANN, F. (2007): "Conclusions: likely and unlikely pasts, possible and impossible futures», en FISCHER-KOWALSKI, M. y HABERL, H. (eds.). Socioecological Transitions and Global Change. Trajectories of Social Metabolism and Land Use. Cheltenham, Edward Elgar, p. 223-255.

GARRABOU, R. y SANZ, J. (1986): «La agricultura española durante el siglo XIX: ¿inmovilismo o cambio? », en GARRABOU, R. y SANZ, J. (ed.). Historia agraria de la España contemporánea, 2. Expansión y crisis (1850-1900). Barcelona, Crítica.

GONZÁLEZ BERNÁLDEZ, F. (1981): Ecología y paisaje. Barcelona.

GONZÁLEZ DE MOLINA, M. (2010a): A guideline to studying the socio-ecological transition in european agriculture, Sociedad Española de Historia Agraria, Docuementos de Trabajo, DT-SEHA, N. 10-06.

GONZÁLEZ DE MOLINA, M. (2010b): «Crecimiento agrario y sostenibilidad de la agricultura española de los siglos XVIII y XIX», en Robledo, R. (ed.). Sombras del progreso. Las huellas de la historia agraria. Barcelona, Crítica, p. 321-352.

GONZÁLEZ DE MOLINA, M. y GUZMÁN, G. (2006): Tras los pasos de la insustentabilidad. Agricultura y medio ambiente en perspectiva bistórica (s. XVIIIXX). Barcelona, Icaria.

GONZÁLEZ DE MOLINA, M. y SEVILLA, E. (1991): Minifundio y gran propiedad agraria: estabilidad y cambio en la Alta Andalucía, 17581930, en Saavedra, P. y Villares, R. (eds.), Señores y campesinos en la Península Ibérica, siglos XVIII-XX, Vol. 2. Campesinado y pequeña explotación. Barcelona, Crítica, pp. 88-138.

GONZÁLEZ DE MOLINA, M.; GARCÍA, R.; GUZMÁN, G.; SOTO, D. e INFANTE, J. (2010): Guideline for constructing nutrient balances in historical agricultural systems (And its application to three cases-studies in Southern Spain). Sociedad Española de Historia Agraria, Docuementos de Trabajo, DTSEHA, N. 10-08. 
GUZMÁN, G.I. y GONZÁLEZ DE MOLINA, M. (2009): «Preindustrial agriculture versus organic agriculture. The land cost of sustainability», Land Use Policy, n. 26/2, p. 502-510.

GUZMÁN, J.R. (2004): El palimpsesto cultivado. Historia de los paisajes del olivar andaluz. Sevilla, Consejería de Agricultura y Pesca, Junta de Andalucía.

HABERL, H. y KRAUSMANN, F. (2007): «The local base of historical agrarian-industrial transition and the interaction between scales», en FischerKowalski, M. y Haberl, H. (eds.). Socioecological Transitions and Global Change. Trajectories of Social Metabolism and Land Use. Cheltenham: Edward Elgar, p. 116-138.

HERNÁNDEZ, R. (2007): «El consumo de aceite de oliva en las fábricas textiles castellanas a finales del Antiguo Régimen: Astudillo, 1792-1807», en V.AA. I Congreso de Cultura del Olivo. Jaén: Instituto de Estudios Giennenses, 2007, p. 139-156.

HORCAS, M. (1990): Baena en el siglo XIX: al crisis del antiguo régimen, 2 vols. Córdoba, Diputación Provincial de Córdoba.

INFANTE, J. (2011): Ecología e historia del olivar andaluz. Un estudio socioambiental de la especialización olivarera en el sur de España (1750-2000). Tesis Doctoral. Sevilla, Universidad Pablo de Olavide, 2011.

INFANTE, J. (2012): El carácter de la especialización olivarera en el sur de España (1750-1930). Sociedad Española de Historia Agraria, Working Papers, 12-01.

IOOC. INTERNATIONAL OLIVE OIL COUNCIL. Survey \& Assessment Division. [En línea] < http,//www.internationaloliveoil.org/web/ aa-ingles/corp/AreasActivitie/economics/AreasActivitie.html> [25 de mayo de 2010]

JONES, C.F. (2010): «A landscape of energy abundance: Anthracite coal canals and the roots of American fossil fuel dependence, 1920-1860», Environmental History, n. 15, p. 449-484.

KRAUSMANN, F. (2001): «Land use and industrial modernization: an empirical analysis of human influence on the functioning of ecosystems in Austria 1830-1995», Land Use Policy, 18, p. 17-26. 
KRAUSMANN, F. (2004): «Milk, manure and muscle power. Livestock and transformation of pre-industrial agriculture in Central Europe», Human Ecology, n. 3, p. 735-772.

KRAUSMANN, F.; SCHANDL, H. y SIEFERLE, R.P. (2008): «Socioecological regime transitions in Austria and the United Kingdom», Ecological Economics, n. 65, p. 187-201.

LANDESCHI, G.B. 1994[1770]: Interpretación delpaisaje agrario de la Toscana en el siglo XVIII. Alicante, Universidad de Alicante.

MALANIMA, P. (2001): «The energy basis for early modern growth, 1650-1820», en Prak, M. (ed.). Early Modern Capitalism. Economic and social change in Europe, 1400-1800. Londres: Routledge, p. 51-68.

MARTÍN, F. (2003): «Conclusiones históricas para la denominación de origen del aceite de la Sierra Sur o Sur de Jaén», Alcalá la Real, Real Cofradía de Nuestra Señora de las Mercedes.

MARTÍNEZ-ALIER, J. (2007): «Marxism, Social Metabolism, and Internacional Trade», en HORNBORG, A., MCNEILL, J.R. y MARTÍNEZALIER, J. (eds.), Rethinking Environmental History. World-System History and Global Environmental Change. Lanhan, Altamira Press, p. 221-237

MARTÍNEZ, M. (1995): Revolución liberal y cambio agrario en la Alta Andalucía. Granada, Universidad de Granada.

MATA OLMO, R. (1987): Pequeña y gran propiedad agrarias en la Depresión del Guadalquivir, siglos XVIII-XX. 2 vols. Madrid, Ministerio de Agricultura, Pesca y Alimentación.

MATAIX, F.J. y BARBANCHO, F. (2007): «El aceite de oliva en la alimentación mediterránea», en VVAA, I Congreso de Cultura del Olivo. Jaén: Instituto de Estudios Giennenses, p. 707-761.

MF, MINISTERIO DE FOMENTO (1887/89): La crisis agrícola y pecuaria, 8 vols. Madrid, Dirección General de Agricultura, Industria y Comercio, Ministerio de Fomento.

MUÑOZ, C.; BELAJ, A.; BARRANCO, D. y RALLO, L. (2004): Olivos monumentales de España. Valencia, Mundiprensa. 
NAVARRO, C. y PARRA, M.A. (2004): «Plantación», en D. BARRANCO, R. FERNÁNDEZ-ESCOBAR y L. RALLO (eds.), El Cultivo del Olivo, Madrid, Mundi Prensa-Junta de Andalucía (5 ed.).

PFISTER, C. (1990): «The early loss of ecological stability in an agrarian region», en BRIMBLECOMBE, P., and PFISTER, C. (eds.). The Silent Countdown. Essays in European Environmental History. Berlin, Springer-Verlag, pp. 37-55.

PONSOT, P. (1986): Atlas de historia económica de de la Baja Andalucía (Siglos XVI-XIX). Sevilla.

RINGROSE, D.R. (1972): Los transportes y el estancamiento económico de España (1750-850). Madrid.

SÁNCHEZ, F. (1988): Extensión de cultivos en España en el siglo XVIII. Madrid, Siglo XXI - Ministerio de Agricultura, Pesca y Alimentación.

SÁNCHEZ, F. (1989): «El olivo y su expansión en el Reino de Jaén durante el siglo XVIII», Boletín del Instituto de Estudios Giennenses, número 138, p. 83-98.

SCHLÖGEL, K. (2007): En el espacio leemos el tiempo. Sobre historia de la civilización y Geopolitica. Madrid, Siruela.

SIEFERLE, R. P. (1990): «The energy system: A basic concept of Environmental History», en BRIMBLECOMBE, P., and PFISTER, C. (eds.), The Silent Countdown. Essays in European Environmental History, Berlin, Springer-Verlag.

SIEFERLE, R. P. (2001): The subterranean forest. Energy Systems and the Industrial Revolution. Cambridge, The White Horse Press.

SMIL, V. (2001): Energías. Una guia ilustrada de la biosfera y la civilización. Barcelona, Crítica.

TELLO, E. (1999): «La formación histórica de los países agrarios mediterráneos: una aproximación coevolutiva», Historia Agraria, Núm. 19, p. $195-212$. 
TELLO, E.; GARRABOU, R. y CUSSÓ, X. (2001): «Tras las huellas del metabolismo social: una propuesta metodológica para analizar el paisaje como humanización del territorio», Instituto de Estudios Ecologistas, Reflexiones (Ciencia y Tecnología), [En línea] <http://www.estudiosecologistas.org/ docs/reflexion/tecnologia/GarrabouTelloCusso.pdf> [17 de julio de 2011]

WRIGLEY, E.A. (1988): Continuity, Chance and Change: The Character of the Industrial Revolution in England. Cambridge, Cambridge University Press.

ZAMBRANA, J.F. (1987); Crisis y modernización del olivar. Madrid, Ministerio de Agricultura, Pesca y Alimentación.

ZAMBRANA, J.F. (2006): El sector primario andaluz en el siglo XX. Sevilla, Instituto de Estadística de Andalucía.

ZOHARY, D. y HOPF, M. (1994): Domestication of plants in the Old World, 2nd edn. Oxford, Clarendon Press. 